\title{
Experimental Study on Local Flame Properties of Hydrogen Added Hydrocarbon Premixed Turbulent Flames"
}

\author{
Masaya NAKAHARA $^{* *}$, Takamori SHIRASUNA ${ }^{* * *}$ and Jun HASHIMOTO ${ }^{* * * *}$ \\ ${ }^{* \star}$ Ehime University, \\ 3 Bunkyo-cho, Matsuyama 790-8577, Japan \\ E-mail: mnakahara@eng.ehime-u.ac.jp \\ ${ }^{* * * K y u s h u ~ U n i v e r s i t y, ~}$ \\ 744 Motooka, Nishi-ku, Fukuoka 819-0395, Japan \\ ****Tsuyama National College of Technology, \\ 624-1 Numa, Tsuyama 708-8509, Japan
}

\begin{abstract}
This experimental study is performed to investigate directly the local flame properties of turbulent propagating flames at the same weak turbulence condition $\left(u^{\prime} / S_{L 0}=1.4\right)$, in order to clarify basically the influence of the addition of hydrogen to lean and rich methane or propane mixtures on its local burning velocity. The mixtures having nearly the same laminar burning velocity with different rates of addition of hydrogen $\delta_{\mathrm{H}}$ are prepared. A two-dimensional sequential laser tomography technique is used to obtain the relationship between the flame shape and the flame displacement in a constant-volume vessel. Some of the key parameters of local flame properties quantitatively measured are the local flame displacement velocity $S_{F}$, curvature and stretch of turbulent flames. Additionally, the Markstein number $M a$ was obtained from outwardly propagating spherical laminar flames, in order to examine the effect of positive stretch on burning velocity. It was found that the trends of the mean values of measured $S_{F}$ with respect to $\delta_{\mathrm{H}}$, the total equivalence ratio $\Phi$ and fuel types corresponded well its turbulent burning velocity. The trend of the obtained $M a$ could explain the $S_{F}$ of turbulent flames only qualitatively. The local burning velocity at the part of turbulent flames with positive stretch and curvature using this $M a, S_{L t}$, attempted to be estimated quantitatively. As a result, a quantitative relationship between the estimated $S_{L t}$ and the $S_{F}$ at positive stretch and curvature of turbulent flames could be observed only for mixtures with $L e>1$ or $M a>0$.
\end{abstract}

Key words: Turbulent Propagating Flame, Hydrogen Added Hydrocarbon, Local Burning Velocity, Markstein Number, Preferential Diffusion, Lewis Number

\section{Introduction}

Future generation combustion devices have goals to achieve very low emissions, fuel variability, and fuel flexibility ${ }^{(1),(2)}$. Lean premixed combustion of Natural Gas NG and Liquefied Petroleum Gas LPG has been studies extensively as one of a promising technique to reduce the exhaust emissions especially of NOx as well as to improve the fuel economy. There, however, are a number of difficulties associated with lean burn operation. One important difficulty of lean burning is that the flames are so weakly burning that stretch of 
turbulence and heat loss can easily cause locally extinction, leading to reduce combustion stability. One of the lean combustion instability problems can be resolved through addition of hydrogen ${ }^{(3)-(6)}$. In the near future, a prospective combustion technology is expected to use refined hydrogen gases derived from NG, coal and biomass. These fuels are considered to be so-called multi-component fuel.

As combustion in most practical systems occurs in the flamelet regime and the performance of combustion devices is governed largely by burning velocity (7),(8), knowledge of the burning velocity of premixed turbulent flames of multi-component fuel mixtures in the flamelet regime is important.

Recent measurements and theories have suggested that the interactions between the preferential diffusion and stretch of laminar premixed flames affect strongly the properties of turbulent premixed flames such as the burning velocity in the flamelet regime ${ }^{(9),(10)}$. Therefore, the Markstein number Ma, which is a crucial parameter that should describe the sensitivity of stretch or curvature on the burning velocity of laminar premixed flames, has been studied widely to aim to elucidate and model the properties of laminar and turbulent premixed flames ${ }^{(11)-(20)}$. However, the majority of studies in $M a$ are limited to single-component fuel mixtures and laminar flames or low stretched flames, except for some works ${ }^{(21)}$. Additionally, it has been proposed recently that preferential diffusion effect, as described by Lewis number, may be related not only to laminar flame instability effects at low turbulence but also to noticeable effects at higher turbulence conditions ${ }^{(10),(22)}$.

In our previous studies ${ }^{(23)}$, the turbulent burning velocity for various mixtures, having nearly the same laminar burning velocity $S_{L 0}$, were examined experimentally. According to almost all of the conventional concepts ${ }^{(24),(25)}$, the local burning velocity of turbulent flames should be equal to the $S_{L 0}$. This hypothesis is clear to be in conflict with our experimental result. That is, the mean local burning velocity $S_{L}$, as the substantial burning velocity of turbulent flames, was found to be able to deviate from the $S_{L 0}$. This deviation is attributed to preferential diffusion effect. In addition, a simple model for predicting turbulent burning velocity was proposed based on the estimated $S_{L}$ instead of the $S_{L 0}$ as a reference. The result suggests that the local burning velocity of turbulent flames can play an important role in determining the turbulent burning velocity.

The present experimental study is performed to examine directly the local flame properties of turbulent propagating flames with hydrogen added hydrocarbon mixtures as two-components fuel mixtures for the same turbulence level of $u ' / S_{L 0}=1.4$, including the $M a$ obtained from outwardly propagating spherical laminar flames, in order to investigate fundamentally the local burning velocity of turbulent flames for multi-component fuel mixtures. Hydrogen added methane or propane mixtures having nearly the same $S_{L 0}$ with different addition rates of hydrogen and equivalence ratios as lean and rich are prepared for experiments. The combustion chamber is a constant volume vessel where approximately isotropic and homogeneous turbulence can be generated near the central region. A two-dimensional laser tomography technique is used to obtain the sequential and quantitative relationship between flame shape and motion. The local flame displacement velocity, curvature, stretch and Karlovitz number of flamelets of turbulent flames are quantitatively measured as key parameters determining its properties of local burning velocity. Additionally, an attempt is made to examine quantitatively the relationship between the displacement velocity on the positively stretched part of turbulent flames, at which is almost equivalent to the convex part of turbulent flame toward the unburned mixture, and the change in the burning velocity on that part due to the $M a$ as characteristic sensitivity of each mixture to positive stretch. Overall, this study examines the local burning velocity of premixed turbulent flames with special attentions to the effect of flame stretch due to the change of a flame surface area. Finally, this observed phenomenon is also discussed based on the concept of the Lewis number effect on the turbulent burning 


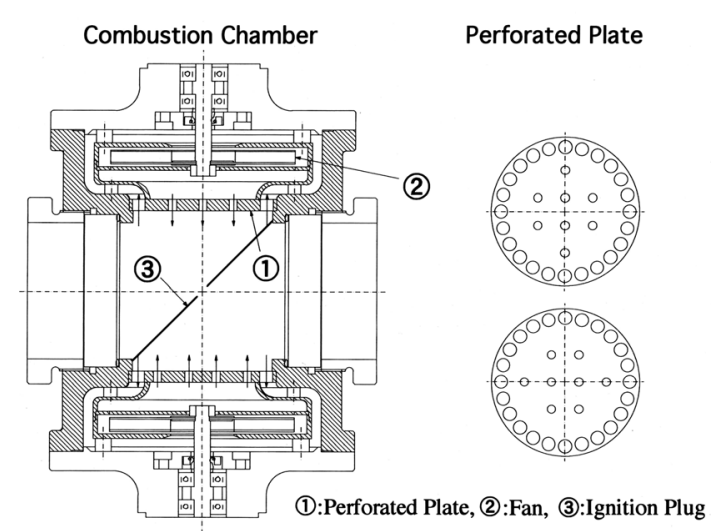

Fig. 1 Cross-sectional view of combustion chamber

velocity.

\section{Experimental Procedure}

\subsection{Apparatus and procedure}

Experimental apparatus and procedure are the same as that used in our previous studies ${ }^{(20),(26)}$. The combustion chamber used as shown in Fig. 1 is a nearly spherical vessel with an equivalent inner diameter of about $100 \mathrm{~mm}$. It is fixed with four transparent windows of $85 \mathrm{~mm}$ diameter at four rectangular sides, and two perforated plates of $90 \mathrm{~mm}$ diameter at the other two sides. Behind each perforated plate, a fan is equipped to mix gases and generate nearly isotropic and homogeneous turbulence in the central region of the chamber.

The optical system for laser tomography is used to obtain the sequential tomograms of propagating flames. For the laser sheet light source, a continuous-wave Nd:YAG laser (5W, $532 \mathrm{~nm}$ ) is adopted. The laser beam is transformed with three cylindrical lenses to produce a sheet, which has a thickness of under $0.1 \mathrm{~mm}$ and a width of about $73 \mathrm{~mm}$ at the measurement location, in the middle plane of the combustion chamber. $\mathrm{TiO}_{2}$ powder is used as the seeding particles. The scattered light is imaged using a high-speed digital camera, which has a resolution of $512 \times 512$ pixels, 8 bit and an acquisition rate of 2000 frames/s (exposure time $=18 \mu \mathrm{s}$ ), and band-pass filters are also mounted in front of the camera. The captured image data were transferred to a computer. The spatial resolution of images results in $0.12 \mathrm{~mm} /$ pixel.

The experiments are conducted as follows. The mixtures are concocted in the chamber according to the partial pressure of components and then ignited at the vessel center under the desired turbulence intensity and atmospheric condition where the ignition energy, the initial pressure $P_{0}$ and temperature $T_{0}$ are $2.0 \mathrm{~J}$, about $0.101 \mathrm{MPa}$ and $298 \mathrm{~K}$, respectively. The sequential tomography for each mixture is repeated five times for laminar combustion and ten times for turbulent combustion at the same condition, respectively.

The turbulent combustion experiments are carried out for one turbulence level $u^{\prime} / S_{L 0}=1.4$ corresponding fan speeds of $1000 \mathrm{rpm}$ as shown in Table 1. Here, $u$ ' is the turbulence intensity defined as the root-mean-squares of the velocity fluctuations ( $u$ ' being about $0.35 \mathrm{~m} / \mathrm{s}$ at $1000 \mathrm{rpm}), S_{L 0}$ the laminar burning velocity, $L_{f}$ the longitudinal integral length scale, $\eta_{0}$ the preheat zone thickness $\left(=a_{0} / S_{L 0}\right), \quad D a_{l}$ the Damköhler number $\left(=L_{f} / u^{\prime} \cdot S_{L 0} / \eta_{0}\right), R e_{l}$ the Reynolds number $\left(=L_{f} u^{\prime} / v\right), a_{0}$ the thermal diffusivity and $v$ the kinematic viscosity. Besides, $S_{L 0}$ is measured by the pressure history of combustion in the chamber ${ }^{(23),(27)}$ in the early stages of combustion where the pressure rise was 0.01 to $0.02 \mathrm{MPa}$. The turbulent burning velocity $S_{T}$ in Fig. 2 is also calculated by the relation ${ }^{(23)}$, $S_{T} / S_{L 0} \approx(\mathrm{d} p / d t)_{T} /(d p / d t)_{L 0}$, where $d p / d t$ is the pressure increase rate, and subscripts $T$ and $L 0$ 
Table 1 Properties of mixtures and test condition

\begin{tabular}{|c|c|c|c|c|c|c|c|c|c|c|c|c|}
\hline \multirow{2}{*}{ Mixture } & \multirow{2}{*}{$\Phi$} & \multicolumn{5}{|c|}{ Components [mol] } & \multirow{2}{*}{$\begin{array}{r}S_{L 0} \\
\mathrm{~cm} / \mathrm{s} \\
\end{array}$} & \multirow{2}{*}{$\mathrm{Le}$} & \multicolumn{4}{|c|}{ Fan Speed $1000 \mathrm{rpm}$} \\
\hline & & $\mathrm{H}_{2}$ & $\mathrm{CH}_{4}$ & $\mathrm{C}_{3} \mathrm{H}_{8}$ & $\mathrm{O}_{2}$ & $\mathrm{~N}_{2}$ & & & $u^{\prime} / S_{L 0}$ & $L_{f} / \eta_{0}$ & $D a$ & $R e_{l}$ \\
\hline M08-25NH00 & 0.8 & 0.0 & 1.0 & $\overline{-}$ & 2.50 & 9.63 & 25.35 & 0.89 & 1.38 & 33.7 & 24.3 & 63.1 \\
\hline M08-25NH02 & 0.8 & 0.2 & 0.8 & - & 2.13 & 8.93 & 24.79 & $(0.80)$ & 1.42 & 31.2 & 22.1 & 62.2 \\
\hline M08-25NH05 & 0.8 & 0.5 & 0.5 & - & 1.56 & 7.42 & 25.44 & $0.67)$ & 1.38 & 29.0 & 1.0 & 0.4 \\
\hline M08-25NH08 & 0.8 & 0.8 & 0.2 & - & 1.00 & 6.45 & 25.09 & $(0.53)$ & 1.40 & 25.2 & 18.0 & 58.2 \\
\hline M08-25NH10 & 0.8 & 1.0 & 0.0 & - & 0.63 & 6.13 & 24.71 & 0.42 & 1.42 & 22.7 & 15.9 & 56.5 \\
\hline ב12-25NH00 & 1.2 & 0.0 & 1.0 & - & 1.67 & 6.67 & 24.40 & 0.93 & 1.44 & 32.3 & 22.5 & 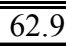 \\
\hline M12-2 & 1.2 & 0.2 & 0.8 & - & 1.42 & 6.02 & 24.76 & 0.99 & 1.42 & 30.5 & 21.5 & 61.6 \\
\hline M12-25NH05 & 1.2 & 0.5 & 0.5 & - & 1.04 & 5.10 & 25.09 & 1.09 & $x$ & - & - & - \\
\hline M12-25NH10 & 1.2 & 1.0 & 0.0 & - & 0.42 & 5.02 & 25.10 & 1.29 & 1.40 & 21.5 & 15.3 & 55.0 \\
\hline P08-25NH00 & 0.8 & 0.0 & - & 1.0 & 6.25 & 25.63 & 24.75 & 1.57 & 1.42 & 35.5 & 25.1 & $\overline{66.7}$ \\
\hline P08-25NH02 & 0.8 & 0.2 & - & 0.8 & 5.13 & 21.27 & 25.45 & $(1.34)$ & 1.38 & 35.5 & 25.8 & 66.2 \\
\hline P08-25NH05 & 0.8 & 0.5 & - & 0.5 & 3.44 & 15.30 & 25.26 & $(1.00)$ & 1.39 & 33.0 & 23.8 & 64.8 \\
\hline P08-25NH08 & 0.8 & 0.8 & - & 0.2 & 1.75 & 9.31 & 25.18 & $(0.66)$ & 1.39 & 28.5 & 20.4 & 61.6 \\
\hline $\begin{array}{l}\text { P08-25NH10 } \\
\end{array}$ & 0.8 & 1.0 & - & 0.0 & 0.63 & 6.13 & 24.71 & 0.42 & 1.42 & 22.7 & 15.9 & 56.5 \\
\hline P12-25NH00 & 1.2 & 0.0 & - & $\overline{1.0}$ & 4.17 & 18.54 & 24.97 & 0.89 & 1.40 & 36.8 & 26.2 & $\overline{68.0}$ \\
\hline P12-25NH02 & 1.2 & 0.2 & - & 0.8 & 3.42 & 15.38 & 24.66 & 0.91 & 1.42 & 35.0 & 24.6 & 67.3 \\
\hline P12-25NH05 & 1.2 & 0.5 & - & 0.5 & 2.29 & 11.02 & 25.11 & 0.97 & 1.40 & 32.5 & 23.3 & 65.3 \\
\hline $\mathrm{P} 12-2$ & 1.2 & 0.8 & - & 0.2 & 1.17 & 6.62 & 25.12 & 1.11 & 1.40 & 26.9 & 19.2 & 60.9 \\
\hline P12-25NH10 & 1.2 & 1.0 & - & 0.0 & 0.42 & 5.02 & 25.10 & 1.29 & 1.40 & 21.5 & 15.3 & 55.0 \\
\hline
\end{tabular}

designate turbulent and laminar combustion, respectively.

\subsection{Properties of mixtures}

The hydrogen added hydrocarbon mixtures as the two-component fuel mixtures used in this study are listed in Table 1. Methane and propane are adopted as hydrocarbon fuel. The former is a lighter hydrocarbon with higher diffusivity than oxygen as the primary component of $\mathrm{NG}$, and the latter is a heavier hydrocarbon with lower diffusivity as a typical component of LPG. The mixtures with different

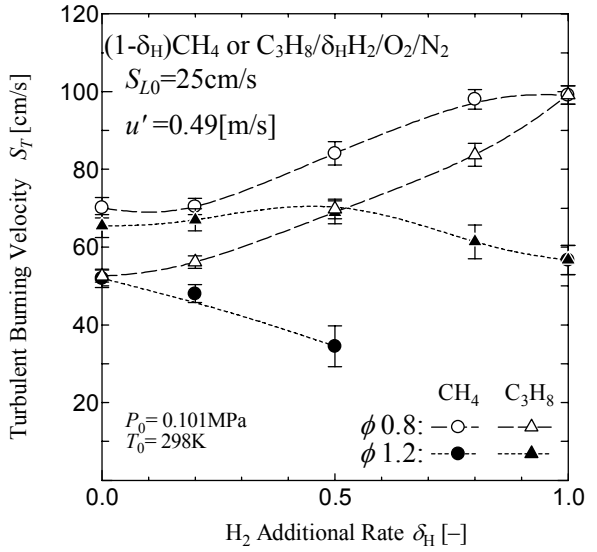

Fig. 2 Variation of $S_{T}$ with $\delta_{\mathrm{H}}$, $\Phi$ and fuel types at $u^{\prime}=0.49 \mathrm{~m} / \mathrm{s}$. equivalence ratios and hydrogen additional rates are prepared while maintaining the $S_{L 0}$ at approximately $25 \mathrm{~cm} / \mathrm{s}$, by adding nitrogen to two-component fuel air mixtures. Due to adopting the mixtures having the same $S_{L 0}$ instead of the conventional fuel air mixtures, the local flame properties of turbulent flames can be examined under almost the same turbulence condition.

In Table 1, $\Phi$ denotes the total equivalence ratio ${ }^{(28)}$ based on the numbers of carbon and hydrogen atoms of two fuels as follows; $\Phi=\left[(\mathrm{x}+\mathrm{y} / 4)\left(1-\delta_{\mathrm{H}}\right)+(1 / 2) \delta_{\mathrm{H}}\right] / \mathrm{X}_{0}$, where the mixture composition is expressed as $\left(1-\delta_{\mathrm{H}}\right) \mathrm{C}_{\mathrm{x}} \mathrm{H}_{\mathrm{y}}+\delta_{\mathrm{H}} \mathrm{H}_{2}+\mathrm{X}_{0} \mathrm{O}_{2}+\mathrm{X}_{\mathrm{N}} \mathrm{N}_{2}$. Here, $\delta_{\mathrm{H}}$ represents the rate of addition as the volume fraction of hydrogen among the total fuel gases. In this experiment, the values of $\Phi$ are fixed at 0.8 and 1.2 , and $\delta_{\mathrm{H}}$ is varied as $0,0.2,0.5,0.8$ and 1.0. But hydrogen-methane mixtures having $\Phi=1.2, \delta_{\mathrm{H}}=0.8$ and $S_{L 0}=25 \mathrm{~cm} / \mathrm{s}(\mathrm{M} 12-25 \mathrm{NH} 08)$ could not be prepared by means of the $2.0 \mathrm{~J}$ of ignition energy used in this study. The turbulent flame of M12-25NH05 mixture was not also taken by tomography. And Le is the Lewis number defined as $a_{0} / D_{d}$, where $D_{d}$ the diffusion coefficient of deficient reactant, however the Lewis numbers of lean two-component fuel mixtures (putted in parentheses in Table 1) are estimated from a linear interpolation of single-component values; $L e=L e_{1} \cdot\left(1-\delta_{\mathrm{H}}\right)+L e_{2} \cdot \delta_{\mathrm{H}}$, where $L e_{1}$ and $L e_{2}$ are Lewis numbers of methane or propane and hydrogen, respectively. 
Figure 2 shows the variation of the measured $S_{T}$ with respect to $\delta_{\mathrm{H}}$ at $u^{\prime}=0.49 \mathrm{~m} / \mathrm{s}$ for mixtures in Table 1 . From Fig. 2, a distinct difference in the measured $S_{T}$ at the same $u^{\prime}$ is seen among two-component fuel mixtures having different $\delta_{\mathrm{H}}$, even under nearly the same $S_{L 0}$. In addition, a noticeable difference exists between the changes in the $S_{T}$ of lean mixtures and those of rich mixtures as $\delta_{\mathrm{H}}$ increases. For lean mixtures, the $S_{T}$ at the same $u$ ' increases almost monotonically as $\delta_{\mathrm{H}}$ increases. For rich mixtures, however, the changes in the $S_{T}$ do not show such a monotonic trend. In our previous studies ${ }^{(28)}$, the phenomenon in Fig. 2 has been discussed on the basis of the preferential diffusion effect on the local burning velocity.

\subsection{Analytical method of local flame properties of laminar and turbulent flames}

In order to investigate quantitatively the local burning velocity of turbulent flames, the local flame displacement velocity of turbulent flames $S_{F}$ is obtained directly from tomograms, according to the same method used in our previous studies ${ }^{(20),(26)}$ :

$$
S_{F}=\left(\rho_{b} / \rho_{u}\right) \cdot V_{F}
$$

where $\rho_{b}$ and $\rho_{u}$ are the density of burned gas and unburned mixture respectively at 0.101 $\mathrm{MPa}$, and $V_{F}$ denotes the local flame propagation speed calculated based on the normal vector at each point, which is detected by converting the grayscale image to a binary, as sketched in Fig. 3. The curvature $1 / r$ is also obtained to examine the configuration characteristics of turbulent flames, where the curvature of the convex part toward the unburned mixture is defined as positive.

Owing to the symmetrical configuration of flames, only the upper parts of images from the center of chamber are analyzed. $S_{F}$ by Eq. (1) may be slightly underestimated due to three-dimensional effects. Additionally, the obtained $S_{F}$ is not considered as the local gas velocity which is necessary for estimating the accurate local burning velocity such as the so-called fuel consumption velocity. In this study, the obtained $S_{F}$ is evaluated statistically as a scalar value ${ }^{(17),(20),(26)}$.

Because of constant volume operation, $S_{F}$ might be affected by the progress rate of flame propagation, because the pressure in the combustion chamber increases slightly and the flame front grows in a spherical manner with flame propagation. A means to remove its influence is adopted from an earlier study ${ }^{(20),(26)}$. That is, for the discussion of analyzed results, the flame images taken at the same condition as the progress rate $\left(R_{A} / R_{C}\right)^{3}$ being about 0.018 are used, where $R_{A}$ and $R_{C}$ denote the equivalent radius based on the burned area of $2 \mathrm{D}$ flame image and that based on the chamber volume $\left(R_{C}=61 \mathrm{~mm}\right)$, respectively.

Additionally, the flame stretch is deduced from sequential 2D flame images. The general expression of the flame stretch $K^{(29)}$ is determined as the fractional time rate of change of a flame surface element of area $A$ :

$$
K=1 / A \cdot d A / d t
$$

Accordingly, if $K_{l}$ denotes for outwardly propagating spherical laminar flames, Eq. (2) can be simplified by just using a time history of the flame radius $r_{f}$ as follows ${ }^{(15)}$ :

$K_{l}=2 / r_{f} \cdot\left(d r_{f} / d t\right)$

As for $K_{T}$ representing $K$ of turbulent flames $\left(=1 / A_{T} \cdot d A_{T} / d t\right)$, the definition of $K_{T}$ seems not as simple as that for laminar flames. In this study, the area of turbulent-flame element $\left(A_{T}\right)$ in $K_{T}$ is determined as sketched in Fig. 3. Then, $d A_{T}$ at each detected point can be approximately calculated based on the length of chord between neighboring points on 
flame1, $l_{l}$, and that between the points where the normal vectors on the points on flame1 cross the flame $2, l_{2}$, as follows:

$$
d A_{T}=A_{2}-A_{1}=l_{2}^{2}-l_{1}^{2}
$$

where flame 1 denotes an image concerned for analysis and flame 2 denotes the successive image of the flame. It was assumed that the direction of flame movement was at right angle to the tangential line on the point of flamel because the flame travel period from flame 1 to flame2 was shorter, and the surface area of each flame element was a square of the chord of two neighboring points because the distance between the analyzed points was also short enough.

The number of analyzed points for turbulent flames was about 1800 to keep the accuracy of measurements, by using 10 turbulent flames at $\left(R_{A} / R_{C}\right)^{3} \approx 0.018$ for each mixture.

\section{Results and Discussion}

\subsection{Local Flame Displacement Velocity}

A typical analyzed result at $\left(R_{A} / R_{C}\right)^{3} \approx 0.018$ is shown in Fig. 4 for a hydrogen-added propane mixture with $\Phi=0.8$ and $\delta_{\mathrm{H}}=0.5$ at $u$ ' $/ S_{L 0}=1.4$. Figure 4 presents the probability density function (pdf) of $\eta_{0} / r$, pdf of the Karlovitz number based on Eq. (4), $K a_{T}\left(=K_{T} \cdot \eta_{0} / S_{L 0}\right)$, and the distribution of $S_{F} / S_{L 0}$ with respect to $\eta_{0} / r$ and $K a_{T}$, respectively. It is clear from Fig. 4 that the values of $\eta_{0} / r, K a_{T}$ and $S_{F}$ are distributed over a wider range than those obtained in the laminar combustion ${ }^{(20),(26)}$, even under $u ' / S_{L 0}=1.4$. Additionally, the same interesting tendencies as those in previous studies ${ }^{(20),(26)}$ can be observed from Fig. 4; the $S_{F} / S_{L 0}$ with $\eta_{0} / r$ tends to be distributed symmetrically with respect to positive and negative curvatures, however such a symmetrical distribution cannot be seen between $S_{F} / S_{L 0}$ and $K a_{T}$. The $S_{F} / S_{L 0}$ was distributed over at a larger positive value of $K a_{T}$ in comparison with the negative side of $K a_{T}$. The number of the points of positive curvature and stretch are also larger than that of negative ones. Similar dependencies follow for the other mixtures. These results suggest that the combustion characteristics of the convex part toward the unburned mixture with positive stretch can possibly govern the mean local burning velocity and the turbulent burning velocity.

Figure 5 shows variations of the mean values of $S_{F}$ on positive curvatures $S_{F, m u}$ and those on negative curvatures $S_{F, m b}$ normalized by $S_{L 0}$ at $u^{\prime} / S_{L 0}=1.4$ with $\delta_{\mathrm{H}}$ and $\Phi$ for (a)

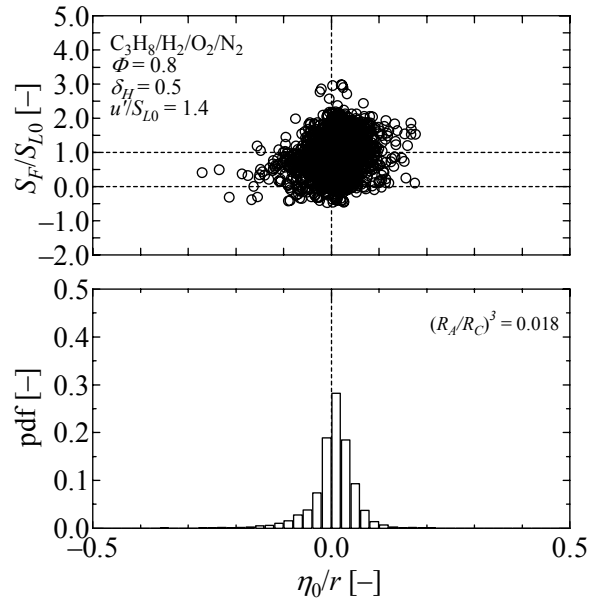

(a) $\eta_{0} / r$

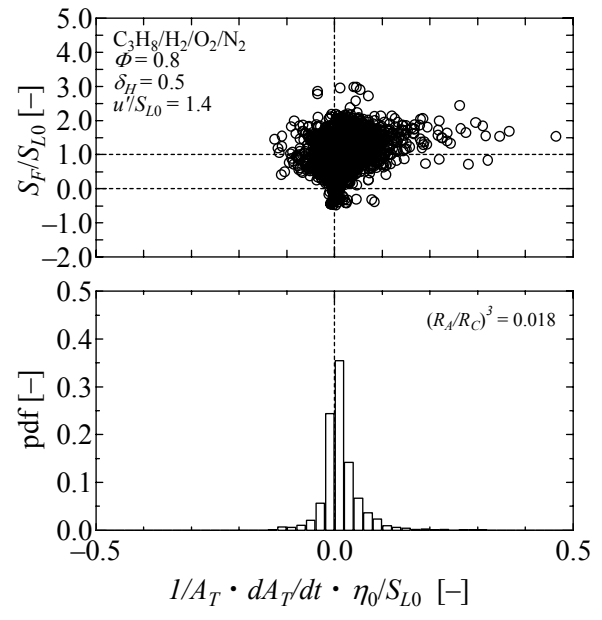

(b) $K a_{T}$

Fig. 4 Typical pdf of curvature normalized by estimation of flame front thickness $\eta_{0} / r$ and Karlovitz number $K a_{T}\left(=1 / A_{T} \cdot d A_{T} / d t \cdot \eta_{0} / S_{L 0}\right)$, and distribution of normalized local flame displacement velocity $S_{F} / S_{L 0}$ for turbulent flames at $u$ ' $/ S_{L 0}=1.4$. [ $\mathrm{H}_{2}$-added $\mathrm{C}_{3} \mathrm{H}_{8}$ mixture with $\Phi=0.8, \delta_{\mathrm{H}}=0.5$, $\left.\left(R_{A} / R_{C}\right)^{3} \approx 0.018\right]$. 


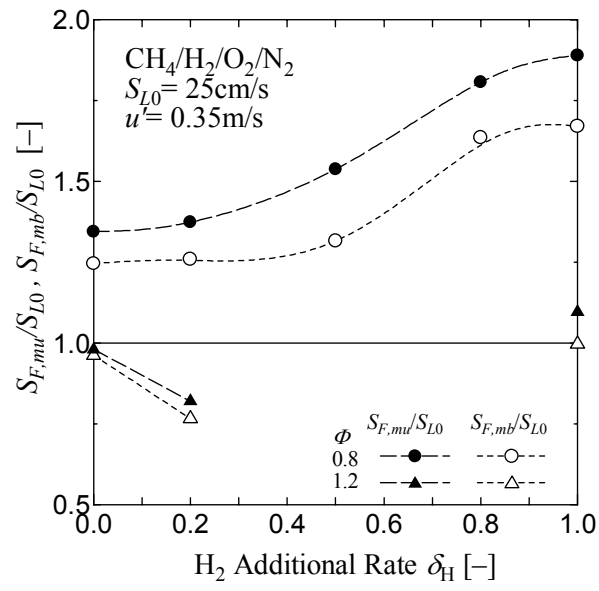

(a) $\mathrm{H}_{2}$-added $\mathrm{CH}_{4}$

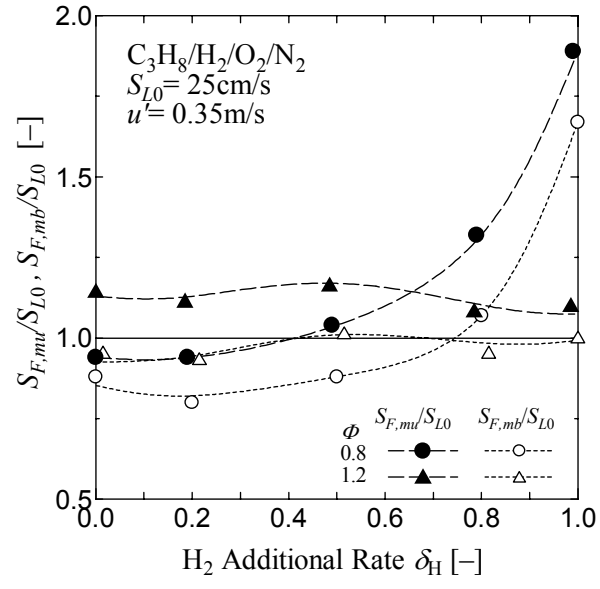

(b) $\mathrm{H}_{2}$-addded $\mathrm{C}_{3} \mathrm{H}_{8}$

Fig. 5 Variation of the normalized mean value of $S_{F}$ on positive and negative curvature, $S_{F, m u} / S_{L 0}$ and $S_{F, m b} / S_{L 0}$, with $\delta_{\mathrm{H}}, \Phi$ and fuel types, at $u^{\prime} / S_{L 0}=1.4$.

hydrogen-added methane and (b) hydrogenadded propane mixtures. As mentioned in $\S 2.2$, there are a few available data for rich hydrogen-added methane mixtures. It is observed that the values of $S_{F, m u} / S_{L 0}$ tend to become larger than those of $S_{F, m b} / S_{L 0}$, but differences between $S_{F, m u} / S_{L 0}$ and $S_{F, m b} / S_{L 0}$ for rich hydrogen-added methane mixtures are a little as compared with the other mixtures.

Figure 6 shows the variation of the mean value of $S_{F}$ on the whole flame front $S_{F, m}$ normalized by $S_{L 0}$ with $\delta_{\mathrm{H}}$, $\Phi$ and fuel types. It is clear from Fig. 6 that $S_{F, m} / S_{L 0}$ for

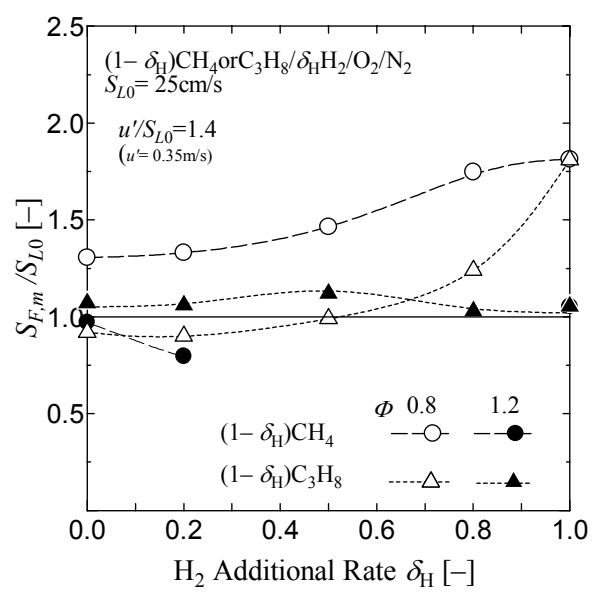

Fig. 6 Variation of the normalized mean values of $S_{F}, S_{F, m} / S_{L 0}$, with $\delta_{\mathrm{H}}$, at $u^{\prime} / S_{L 0}=1.4$.

lean mixtures tends to increase

monotonically with increasing $\delta_{\mathrm{H}}$, regardless of hydrocarbon fuel types. For rich mixtures, however, the changes in the $S_{F, m} / S_{L 0}$ do not show such a monotonic trend. The $S_{F, m} / S_{L 0}$ of rich hydrogen-added methane mixture with $\delta_{\mathrm{H}}=0.0$ shows to be almost the same value as that with $\delta_{\mathrm{H}}=1.0$, and $S_{F, m} / S_{L 0}$ of mixture with $\delta_{\mathrm{H}}=0.2$ is smaller than that with $\delta_{\mathrm{H}}=0.0$. The $S_{F, m} / S_{L 0}$ of rich hydrogen-added propane mixtures also shows a peak at $\delta_{\mathrm{H}}=0.5$. These tendencies correspond well with the trends of $S_{T}$ in Fig. 2.

From these results, it appears again that the mean local burning velocity of turbulent flame, which is approximately the $S_{F, m}$ obtained in this study, can play an important role in the turbulent burning velocity characteristics. Thus, the establishment of turbulent burning velocity model of multi-component fueled mixtures needs to take the local burning velocity into consideration.

\subsection{Effect of positive stretch due to Markstein number on the local burning velocity of turbulent flames}

In our previous study ${ }^{(26)}$, it was obtained that there was a meaningful relationship between $S_{F}$ of turbulent flames and Markstein number $M a$ of laminar flames. So, this section examines the relation between $S_{F}$ and $M a$.

First, the $M a$ for outwardly propagating spherical laminar flames can be determined from the following expression proposed by Faeth et al. ${ }^{(9),(15)}$ :

$$
S_{L \infty} / S_{L l}=1+M a \cdot K a_{l}
$$


where $S_{L l}$ is the burning velocity of the spherical laminar flame relative to the unburned mixture $\left[=\left(\rho_{b} / \rho_{u}\right) \cdot d r_{f} / d t\right.$, i.e., stretched laminar burning velocity], and $S_{L \infty}$ the value of $S_{L l}$ when the flame stretch is 0 (which is almost the same as $S_{L 0}$ in this study), and $K a_{l}$ the Karlovitz number based on Eq. (3) $\left[=K_{l} \cdot\left(\eta_{0 l} / S_{L l}\right)=\left(\left(2 / r_{f}\right) d r_{f} / d t\right) \cdot\left(a_{0}\right.\right.$ $\left.\left./ S_{L l}^{2}\right)\right]$.

Therefore, $M a$ can be approximated by using flame radii obtained from the sequential tomograms of outwardly propagating spherical laminar flames (20),(26). According to Eq. (5), $S_{L l} / S_{L \infty}$ has the inclination to increase with decreasing $M a$ at the same $K a_{l}$. Figure 7 shows the estimated $M a$ against $\delta_{\mathrm{H}}$ for mixtures. It is clear from Fig. 7 that in the case of lean hydrogen-added methane and propane premixed spherical flames $M a$ tends to decrease monotonically with decreasing the hydrogen addition. On the other hand, in the case of fuel-rich flames, the $M a$ with $\delta_{\mathrm{H}}$ shows no such tendency.

Next, due to the similarity on the flame configuration and flame stretch between the outwardly propagating spherical laminar flames and the convex part of turbulent flames toward the unburned mixture, both flames have basically positive stretch and curvature. Accordingly, the relationship between estimated $M a$ and $S_{F, m u} / S_{L 0}$ are examined as shown in Fig. 8. It is found from Fig. 8 that $S_{F, m u} / S_{L 0}$ tends to increase with decreasing $M a$, irrespective of $\delta_{\mathrm{H}}, \Phi$ and fuel types. This tendency accords with Eq. (5) as $S_{L /} / S_{L \infty}$ tends to increase with decreasing $M a$ at the same $K a_{l}$. This suggests that there exists a qualitative relationship between the $M a$ of laminar flames and the $S_{F}$ of turbulent flames.

Figure 9 shows the variation of $S_{F, m u} / S_{L 0}$ at $u^{\prime} / S_{L 0}=1.4$ with the Lewis number $L e$ in Table 1 for comparison with $M a$. In this study, even if the Le for lean two-component fuel mixtures is an estimated value based on just the molar fraction of two fuels instead of such a heat release weighted effective Lewis number ${ }^{(30)}$, there exits an obvious relationship between the $S_{F, m u} / S_{L 0}$ and $L e$, as similar to that between $S_{F, m u} / S_{L 0}$ and $M a$ in Fig. 8. The relationship between $S_{F, m u} / S_{L 0}$ and $L e$, however, seems to be less linear than that between

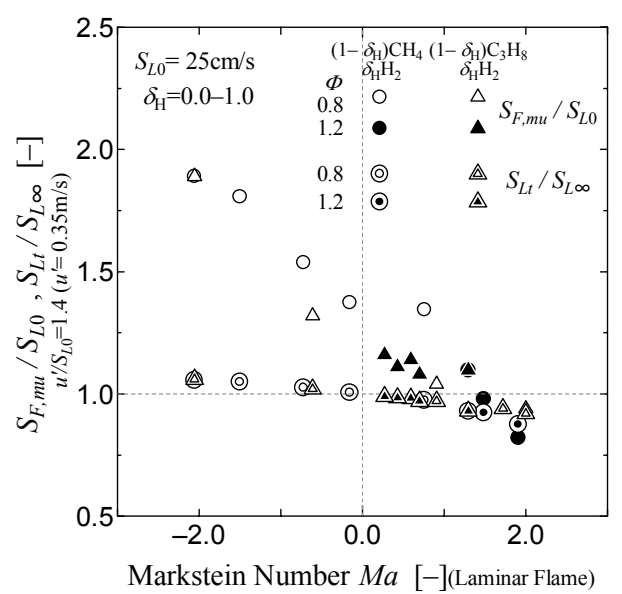

Fig.8 Relationship among the Markstein number $M a$, the $S_{F, m u} / S_{L 0}$, and the $S_{L t} / S_{L \infty}$ estimated by the $M a$.

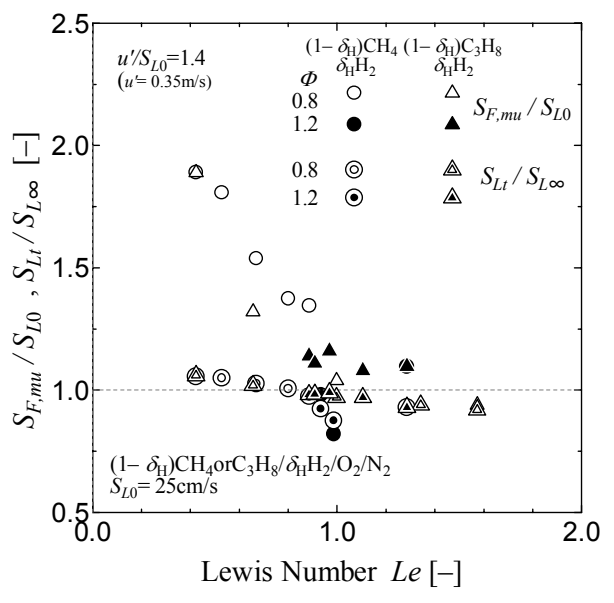

Fig. 9 Relationship among the Lewis number $L e$, the $S_{F, m u} / S_{L 0}$, and the $S_{L t} / S_{L \propto}$ estimated by the $M a$. 
$S_{F, m u} / S_{L 0}$ and $M a$. Additionally, Le has discontinuous value when the equivalence ratio is one. Therefore, the $M a$ could be possibly a suitable parameter for the establishment of a model with respect to the local burning velocity of multi-component fuel mixtures.

Finally, an attempt is also made to examine quantitatively the effect of characteristic positive stretch of each mixture, represented by $M a$ in Fig. 7, on the local burning velocity of turbulent flames, by the same method in our previous study ${ }^{(26)}$. Equation (5) can be rewritten for the convex part of turbulent flames toward the unburned mixture with positive stretch as follows:

$$
S_{L \infty} / S_{L t}=1+M a \cdot K a_{t}
$$

where, $S_{L t}$ is the burning velocity of turbulent flames at $1 / r>0$ and $K_{T}>0$ using the $M a$ obtained by Eq. (5), and $K a_{t}$ is the Karlovitz number based on local properties of turbulent flame as determined according to:

$$
K a_{t}=1 / n\left(\sum^{n} K_{T} \cdot a_{0} / S_{F}^{2}\right), \quad \text { at } 1 / r>0 \& K_{T}>0
$$

In Eq. (7), $n$ is the number of flame-front elements with $1 / r>0$ and $K_{T}>0$.

The estimated values of $S_{L t} / S_{L \infty}$ at $u^{\prime} / S_{L 0}=1.4$ are plotted in Figs. 8 and 9. At $u^{\prime} / S_{L 0}=1.4$, the mean values of $K_{T}\left(=1 / A_{T} \cdot d A_{T} / d t\right)$ in Eq. (7) were varied from about 80 to 130.

Figures 8 and 9 show that $S_{L t} / S_{L \infty}$ as well as $S_{F, m u} / S_{L 0}$ tend to increase with decreasing $M a$ and $L e$. However, it is also clear that the trends of $S_{L t} / S_{L \infty}$ correspond with those of $S_{F, m u} / S_{L 0}$ only qualitatively. That is, for mixtures with larger $L e$ or larger $M a$, differences between $S_{L t} / S_{L \infty}$ and $S_{F, m u} / S_{L 0}$ are smaller, however for $L e<1$ or $M a<0$ the differences are considerably larger and tends to increase with decreasing $L e$ or $M a$. Therefore, this suggests that for turbulent flames with larger $L e$ and $M a$, especially $L e>1$ or $M a>0$, the effect of $M a$ becomes predominant on the change in the local burning velocity at the convex part of turbulent flames toward the unburned mixture with positive stretch. On the other hand, for turbulent flames with $L e<1$ and $\mathrm{Ma}<0$, the other predominant effects can be expected to exist. A notable effect of these is the preferential diffusion, because for $L e<1$ the molecular transport is dominant. From this viewpoint, in the case of methane and hydrogen mixtures, the diffusion coefficient of fuel is larger than that of oxygen (especially hydrogen has larger diffusivity due to its smallest molecular weight), while the diffusion coefficient of propane is smaller than that of oxygen ${ }^{(23),(26)}$. For an example, in the case of lean hydrogen-added mixtures, hydrogen can diffuse more to the convex flame toward the unburned mixture caused by the preferential diffusion. This shows that the local burning velocity at this part of turbulent flame for the larger $\delta_{\mathrm{H}}$ mixtures increases due to fuel being the deficient reactant, because the $L e$ of lean hydrogen-added mixtures decreases and becomes smaller than 1 with increasing $\delta_{\mathrm{H}}$ as shown in Table 1 .

Further consideration with respect to practical influences of the gas flow near flame front and the three-dimensional configuration ${ }^{(31)-(33)}$ may be necessary. However, this study provides useful information to develop an adequacy model of turbulent burning velocity for multi-component fuel mixtures if a quantitative relationship between the local burning velocity and $M a$ was found out, because $M a$ for a given mixture can be estimated by experimental and numerical methods. In addition, there exists the mixtures such as $L e<1$ or $M a<0$ that the change in the local burning velocity of turbulent flames with $\delta_{\mathrm{H}}, \Phi$ and fuel types can not be explained quantitatively by the Markstein number based on the effect of flame stretch on laminar flames.

\section{Conclusions}

The local flame properties of turbulent flames for 16 cases of fuel-lean $(\Phi 0.8)$ and fuel-rich $(\Phi 1.2)$ hydrogen-added methane or propane mixtures are investigated experimentally by using 2D tomograms. The local flame displacement velocity of turbulent flames $S_{F}$ at $u$ ' $/ S_{L 0}=1.4$ was obtained directly to examine the local burning velocity of 
turbulent flames. The Markstein number was also estimated from outwardly propagating spherical laminar flames. The main conclusions were as follows:

(1) The mean values of obtained $S_{F}, S_{F, m}$, for lean methane and propane mixtures tended to increase constantly as the addition rate of hydrogen $\delta_{\mathrm{H}}$ increases, while that for rich mixtures could not show such a constant trend. The trends of $S_{F, m}$ with respect to $\delta_{\mathrm{H}}, \Phi$ and fuel types corresponded well the turbulent burning velocity of these mixtures.

(2) The Markstein number $M a$ obtained from spherical laminar flames could be confirmed to have a good linear relationship to the mean value of $S_{F}$ on convex parts toward the unburned mixture of turbulent flames $S_{F, m u}$ for two-component fuel mixtures. As compared with $M a$, the Lewis number Le based on the diffusion coefficient of deficient reactant showed approximately a linear relation to $S_{F, m u}$.

(3) An attempt was made to estimate the burning velocity $S_{L t}$ on the part of turbulent flames with positive stretch and curvature using the $M a$ obtained from laminar flames, in order to examine quantitatively the effect of $M a$ on the local burning velocity of turbulent flame. A quantitative relationship between $S_{F}$ and $S_{L t}$, however, could be observed only for mixtures with $M a>0$ or $L e>1$.

\section{Acknowledgements}

This study is partially supported by General Sekiyu Research \& Development Encouragement \& Assistance Foundation. We would finally like to thank Prof. Hiroyuki KIDO for useful discussions and advice concerning this material and to Mr. Kenshiro NAKASHIMA and Mr. Syunji UEDA for designing the experimental facility.

\section{References}

(1) Richards, G. A., McMillian, M. M., Gemmen, R. S., Roggers, W. A., and Cully, S. R., Issues for low-emission, fuel-flexible power systems, Prg. Energ. Combust. Sci., Vol.27(2001), pp.141-169.

(2) Chomiak, J., Longwell, J. P., and Sarofim, A.F., Combustion of Low Calorific Values Gases; Problems and Prospects, Prg. Energ. Combust. Sci., Vol.15(1989), pp.109-129.

(3) Yu, G., Law, C. K., and Wu, C. K., Laminar Flame Speeds of Hydrocarbon + Air Mixtures with Hydrogen Addition, Combust. Flame, Vol.63 (1986), pp.339-347.

(4) Kido, H., Huang, S., Tanoue, K., and Nitta, T., Improving the Combustion Performance of Lean Hydrocarbon, JSAE Review, Vol.15, No.2(1994), pp.165-170.

(5) Jackson, G. S., Sai, R., Plaia, J. M., Boggs, C. M., Kiger, K. T., Influence of $\mathrm{H}_{2}$ on the Response of Lean Premixed $\mathrm{CH}_{4}$ Flames to high strained flows, Combust. Flame, Vol.132(2003), pp.503-511.

(6) Hawkes, E. R., and Chen, J.H., Direct numerical simulation of hydrogen-enriched lean premixed methane-air flames, Combust. Flame, Vol.138,(2004), pp.242-258.

(7) Williams, F. A., Progress in knowledge of flamelet structure and extinction, Prg. Energ. Combust. Sci., Vol.26 (2000), pp.657-682..

(8) Peters, N., Laminar Flamelet Concepts in Turbulent Combustion, Proc. Combustion Inst., Vol.21 (1986), pp.1231-1250.

(9) Law, C. K., and Faeth, G. M., Opportunities and challenges of combustion in microgravity, Prg. Energ. Combust. Sci., Vol.20 (1994), pp.65-113.

(10) Lipatnikov, A. N., and Chomiak, J., Molecular transport effects on turbulent flame propagation and structure, Prg. Energ. Combust. Sci., Vol.31 (2005), pp. 1-73.

(11) Markstein, G. H., Non-steady flame Propagation, (1964), p.22, Pergamon, New York.

(12) Clavin, P., Dynamic Behavior of Premixed Flame Fronts in Laminar and Turbulent Flows, Prg. Energ. Combust. Sci., Vol.11 (1985), pp. 1-59.

(13) Law, C. K., Dynamics of Stretched Flames, Proc. Combustion Inst., Vol.22 (1988), pp.1381-1402. 
(14) Searby, G., and Quinard, J., Direct and indirect measurements of Markstein numbers of premixed flames, Combust. Flame, Vol.82 (1990), pp.298-311.

(15) Know, S., Tseng, L.-K., and Faeth, G. M., Laminar Burning Velocities and Transition to Unstable Flames in $\mathrm{H}_{2} / \mathrm{O}_{2} / \mathrm{N}_{2}$ and $\mathrm{C}_{3} \mathrm{H}_{8} / \mathrm{O}_{2} / \mathrm{N}_{2}$ Mixtures, Combust. Flame, Vol.90(1992), pp.230-246.

(16) Bradley, D., Gaskell, P.H., and Gu, X. J., Burning Velocities, Markstein Lengths, and Flame Quenching for Spherical Methane-Air Flames: A Computational Study, Combust. Flame, Vol.104 (1996), pp. 176-198.

(17) Renou,B., Boukhalfa, A., Puechiberty, D., and Trinité, M., Local Scalar Flame Properties of Freely Propagating Premixed Turbulent Flames at Various Lewis Numbers, Combust. Flame, Vol.123(2000), pp.507-521.

(18) Brutscher, T., Zarzalis, N., and Bockhorn, H., An Experimentally Based Approach for The Apace-Averaged Laminar Burning Velocity Used for Modeling Premixed Turbulent Combustion, Proc. Combustion Inst., Vol.29 (2002), pp.1825-1832.

(19) Lawes, M., Ormsby, M.P., Sheppard, C. G. W., and Woolley, R., Variation of Turbulent Burning Rate of Methane, Methanol, and Iso-Octane Air Mixtures with Equivalence Ratio at Elavated Pressure, Combust.Sci.Tech., Vol.177(2005), pp.1273-1289.

(20) Kido, H., Nakahara, M., Nakashima, K. and Hashimoto, J., Influence of Local Flame Displacement Velocity on Turbulent Burning Velocity, Proc. Combustion Inst. Vol.29 (2002), pp.1855-1861.

(21) Mandilas, C., Ormsby, M. P., Sheppard, C. G. W., and Woolley, R., Effects of hydrogen addition on laminar and turbulent premixed methane and iso-octane-air flames, Proc. Combustion Inst., 31 (2006), pp.1443-1450.

(22) Muppala, S. P. R, Aluri, N. K., Dinkelacker, F. and Leipertz, A., Development of an algebraic reaction rate closure for the numerical calculation of turbulent premixed methane, ethylene, and propane/air flames for pressures up to 1.0 MPa, Combust. Flame, Vol.140(2005), pp.257-266.

(23) Kido, H., and Nakahara, M., A Model of Turbulent Burning Velocity taking the Preferential Diffusion Effect into Consideration, JSME International Journal Series B, Vol.41, No.3(1999), pp. 666-673.

(24) Andrews, G. E., Bradley, D. and Lwakabamba, S. B., Turbulence and Turbulent Flame Propagation-A Critical Appraisal, Combust. Flame, Vol.24 (1975), pp.285-304.

(25) Gulder, O. L., Turbulent Premixed Flame Propagation Models for Different Combustion Regimes, Proc. Combustion Inst. Vol.23(1990), pp.743-750.

(26) Nakahara, M., Kido, H., Shirasuna, T., and Hirata, K., Effect of Stretch on Local Burning Velocity of Premixed Turbulent Flames, Jour. Thermal Science and Technology, Vol.2,No.2(2007), pp.268-280.

(27) Lewis, B., and von Elbe, G., Combustion, Flames, and Explosions of Gases, 3rd ed., Academic Press, (1987), p.389.

(28) Kido, H., Nakahara, M., Hashimoto, J., and Barat, D., Turbulent Burning Velocities of Two-Component Fuel Mixtures of Methane, Propane and Hydrogen, JSME Int. Jour., Vol.45, No.2, Ser.B (2002), pp.355-362.

(29) Williams, F. A., Combustion Theory 2nd, The Benjamin/Cummings, (1985), p.349.

(30) C. K. Law., G. Jomaas, and J. K. Bechtold., Cellular instabilities of expanding hydrogen/propane spherical flames at elevated pressures: theory and experiment, Proc. Combust. Inst., 30(2005), pp.159-167.

(31) Furukawa, J. and Williams, F. A., Flamelet Effects on Local Flow in Turbulent Premixed Burning Flames, Combust. Sci. Tech., Vol.170 (2003), pp. 1835-1858.

(32) Gashi, S., Hult, J., Jenkins, K.W., Chakrabort, N., Kaminski, C.F., Curvature and wrinkling of premixed flame kernels - comparisons of OH PLIF and DNS data, Proc. Combustion Inst. Vol.30 (2004), pp. 809-817. 
(33) Tanahashi, M., Sato, M., Shimura, M., and Miyauchi, T., DNS and Combined Laser Diagnostics of Turbulent Combustion, Jour. Thermal Science and Technology, Vol.3, No.3 (2008), pp.391-408. 